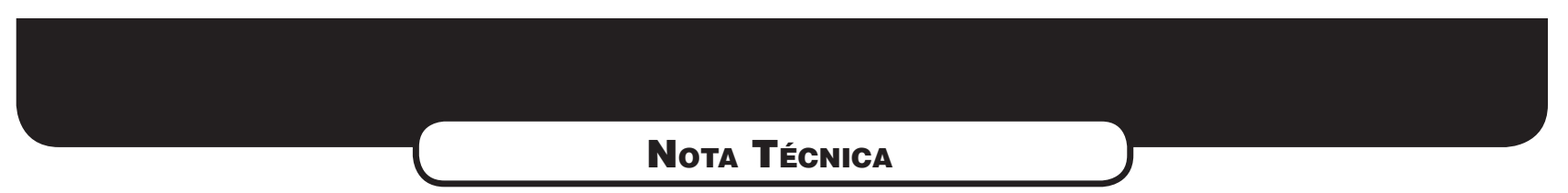

\title{
Planejamento e aspectos ambientais envolvidos na DISPOSIÇÃO FINAL DE LODOS DAS ESTAÇÕES DE TRATAMENTO de água da Região Metropolitana de São Paulo
}

\author{
PlanNing and enVIRONMENTAL ASPECtS INVOLVEd IN THE FINAL DISPOSAL \\ OF SLUDGE FROM WATER TREATMENT PLANTS IN THE METROPOLITAN \\ Area of Sao Paulo
}

GLADYS FERNANDES JANUÁRIO

Engenheira Civil pela EPUSP (1992). Mestre em Engenharia Hidráulica e Sanitária pela EPUSP (2005). Engenheira da SABESP

\section{SIDNEY SECKLER FERREIRA FILHO}

Engenheiro Civil pela EPUSP. Professor Associado do Departamento de Engenharia Hidráulica e Sanitária da Escola Politécnica da Universidade de São Paulo

Recebido: 06/03/06 Aceito: 05/03/07

\section{RESUMO}

A disposição de lodos de estações de tratamento de água (ETAs) de forma ambientalmente correta configura-se em mais um desafio a ser enfrentado pelas companhias de saneamento e tem recebido maior atenção no Brasil e na Região Metropolitana de São Paulo (RMSP) nos últimos anos. O objetivo deste trabalho foi apresentar alternativas existentes de uso e disposição final dos lodos das ETAs da RMSP e, assim sendo, foram pesquisadas várias técnicas de uso e disposição de lodos praticados no Brasil e no mundo e suas condiçōes técnicas e ambientais. Foram avaliadas a quantidade de lodos gerados na RMSP e a existência ou previsão de implantação de sistemas de adensamento e desidratação e, a partir destas informaçōes, foram identificadas alternativas de uso e disposição tecnicamente e ambientalmente exequíveis para os lodos das ETAs da RMSP.

PALAVRAS-CHAVE: Tratamento de água, disposição final de lodo, lodo de estaçóes de tratamento de água.

\begin{abstract}
The disposal of sludge produced by water treatment plants in an environmentally safe manner is one more challenge to be faced by the sanitation companies and has been given more attention in Brazil and in the Metropolitan Area of Sao Paulo (MASP). The purpose of this work is to present the existing alternatives for use and final disposal of sludge produced by the Water Treatment Plants (WTP) of the MASP. In this respect, several techniques for use and disposal of sludge performed in Brazil and worldwide have been investigated, and their technical and environmental conditions. The amount of sludge generated in the MASP and the existence of or the forecast to establish sludge thickening and dewatering systems have been evaluated and based on this information alternatives have been identified for use and disposal which are technically and environmentally feasible for sludge produced by the WTP in the MASP.
\end{abstract}

KEYWORDS: Water treatment, final disposal of sludge, water treatment plants sludge.

\section{INTRODUÇÃO}

O objetivo fundamental das estações de tratamento de água para abastecimento público tem sido produzir água biologicamente e quimicamente segura para o consumo humano, bem como esteticamente agradável. Para isso, utiliza vários processos e operações que, mediante a introdução de produtos químicos, transformam a água bruta, normalmente inadequada para o consumo humano, em água de acordo com os padrôes de potabilidade exigidos. Todo este processo gera, como subprodutos, uma elevada quantidade de resíduos.
Esses resíduos, conhecidos por lodos de ETAs, são derivados dos sólidos suspensos na água bruta e dos produtos químicos adicionados no processo de tratamento, como coagulantes, cal e outros, e apresentam, dessa maneira, características variadas.

Com o crescimento populacional que vem se registrando na Região Metropolitana de São Paulo (RMSP) e o conseqüente aumento das demandas para abastecimento de água, observa-se, também, a crescente geração de lodos nas ETAs, ampliando o problema de seu tratamento e disposição final.
Desse modo, é necessário que o tratamento e a disposição dos lodos se tornem uma parte importante no processo de operação de uma ETA. A prática mais simples a ser adotada é a disposição dos lodos em aterros sanitários. Porém, legislaçôes cada vez mais restritivas, altos custos de transporte e disposição final, bem como a escassez de áreas adequadas em regiōes altamente urbanizadas, têm levado pesquisadores e técnicos à busca de soluções mais econômicas e inteligentes para o uso e disposição final dos lodos.

Devido ao grande volume de lodo gerado nas ETAs da RMSP, o planeja- 
mento de sua disposição deve consistir num programa que oriente a destinação final destes lodos sob os pontos de vista técnico, ambiental e também econômico. Assim, além da alternativa comum de disposição em aterros sanitários, alternativas de disposição e de uso e aplicação dos lodos, transformando-os em insumos, devem ser investigadas com o objetivo de mitigar o problema da disposição final ao reduzir o volume a ser disposto em aterro e aplicar os conceitos de reciclagem e minimização de resíduos, obtendo, como benefício maior, a preservação do meio ambiente. Alguns métodos de uso ou disposição de lodos praticados ou em estudo são: o uso em solos (agricultura, reflorestamento, recuperação de áreas degradadas), fabricação de cimento, fabricação de materiais cerâmicos, lançamento em sistemas de coleta e tratamento de esgoto e recuperação de coagulantes (Cornwell et al, 1999).

O tipo e a qualidade dos lodos gerados e os custos envolvidos em seu tratamento e encaminhamento influenciam consideravelmente a escolha da alternativa de disposição mais adequada. Além disso, é necessário promover uma investigação das possibilidades de mercado existentes que possam viabilizar a utilização dos lodos como insumos, verificando a geração de benefícios tanto para as prestadoras de serviços de saneamento quanto para os demais produtores interessados em utilizar esses lodos (Cornwell et al, 1999).

O objetivo maior do planejamento da disposição final dos lodos de ETAs da RMSP é indicar alternativas existentes de uso e de disposição de lodos praticadas no mundo e no Brasil e identificar alternativas que podem ser utilizadas em cada caso, verificando sua viabilidade técnica, ambiental e econômica.

\section{OBJETIVOS}

Considerando-se o problema crescente referente ao tratamento e à disposição final dos lodos de ETAs e focando-se os sete maiores sistemas produtores de abastecimento de água da RMSP, este trabalho tem como objetivos principais:

- Quantificar os lodos gerados, com base em fórmulas empíricas de cálculo da geração de lodos e através do levantamento de informações nas áreas operacionais das ETAs.
- Verificar a existência ou a previsão de implantação de sistemas de tratamento e disposição final de lodos nas ETAs.

- Identificar alternativas factíveis de uso e disposição de lodo para cada ETA, verificando sua viabilidade técnica e ambiental.

\section{MATERIAIS E MÉTODOS}

Com o objetivo de reunir subsídios para proporcionar uma visão geral das alternativas possíveis de uso e disposição dos lodos gerados nas sete maiores ETAs da RMSP e avaliar seus aspectos técnico e ambiental, o trabalho foi dividido em etapas, a saber:

- Levantamento das características físicas e operacionais das ETAs, com descrição dos processos e produtos químicos utilizados no tratamento e verificação da ocorrência de variação na qualidade da água bruta ao longo do período hidrológico.

- Verificação da expansão prevista para os sistemas produtores de água que, por sua vez, geram aumentos nas quantidades de lodos previstas.

- Verificação da existência ou previsão de implantação de sistemas de tratamento e disposição de lodos nas ETAs.

- Quantificação dos lodos gerados em cada uma das ETAs avaliadas.

- Identificação da viabilidade técnica e ambiental da aplicação das alternativas de uso e disposição final.

\section{Estações de tratamento de água da RMSP}

Atualmente, o Sistema Integrado de Abastecimento da RMSP é constituído por oito Sistemas Produtores localizados em todos os quadrantes da RMSP, contando com oito ETAs que são responsáveis por uma produção média de $65 \mathrm{~m}^{3} / \mathrm{s}$. Estes Sistemas Produtores encontram-se interligados por um complexo sistema de adutoras, elevatórias e reservatórios setoriais, denominado Sistema Adutor Metropolitano (SAM).

Neste trabalho, foram enfocadas as sete maiores ETAs constituintes deste Sistema, responsáveis por mais de $95 \%$ do abastecimento da RMSP. As ETAs, seus respectivos Sistemas Produtores e capacidades nominais são as seguintes:

- ETA Guaraú (Sistema Cantareira): $33,0 \mathrm{~m}^{3} / \mathrm{s}$;
- ETA Alto da Boa Vista (Sistema Guarapiranga): 14,0 m³/s;

- ETA Taiaçupeba (Sistema Alto Tietê): $10,0 \mathrm{~m}^{3} / \mathrm{s}$;

- ETA Rio Grande (Sistema Rio Grande): $5,0 \mathrm{~m}^{3} / \mathrm{s}$;

- ETA Casa Grande (Sistema Rio Claro): $4,0 \mathrm{~m}^{3} / \mathrm{s}$;

- ETA Morro Grande (Sistema Alto Cotia): $1,2 \mathrm{~m}^{3} / \mathrm{s}$;

- ETA Baixo Cotia (Sistema Baixo Cotia): $0,9 \mathrm{~m}^{3} / \mathrm{s}$.

Todas as sete ETAs empregam tratamento convencional completo, dotado de coagulação, floculação, sedimentação, filtração, fluoretação e correção final do $\mathrm{pH}$.

\section{Ampliação das capacidades das ETÁs da RMSP}

As informações sobre previsão das demandas de abastecimento e aumento de capacidade de produção das ETAs da RMSP, apresentadas a seguir, foram obtidas do estudo de Revisão e Atualização do Plano Diretor de Abastecimento de Água da RMSP - PDAA (ENCIBRA; HIDROCONSULT, 2004).

As demandas de água projetadas para o atendimento da RMSP através do Sistema Integrado variam de $64,5 \mathrm{~m}^{3} / \mathrm{s}$ (vazão média de 2000) a $80,8 \mathrm{~m}^{3} / \mathrm{s}$ (vazão média prevista para 2025). Segundo o PDAA, o atendimento a essas demandas pelo Sistema Integrado será feito pelos sistemas produtores existentes, com a ampliação de três dos atuais oito sistemas e com a implantação de um novo sistema, conforme apresentado na Tabela 1 .

\section{Quantificação dos lodos das ETAs da RMSP}

Para o cálculo da estimativa de lodo gerado, foi utilizada uma fórmula empírica para a determinação do balanço de massa das ETAs estudadas, utilizando dados de produtos químicos empregados e características de qualidade da água bruta do ano de 2003 (valores médios mensais).

A fórmula utilizada foi a da Water Research Center (WRC) como segue (Saron e Leite, 2001):

$\mathrm{P}=(1,2 \cdot \mathrm{T}+0,07 \cdot \mathrm{C}+\mathrm{k} \cdot \mathrm{D}+\mathrm{A})$

$\mathrm{P}=$ produção de sólidos ( $\mathrm{g}$ de matéria seca / $\mathrm{m}^{3}$ de água tratada)

$\mathrm{T}=$ turbidez da água bruta (UT) 
$\mathrm{C}=$ cor aparente da água bruta $(\mathrm{uH})$

$\mathrm{D}=$ dosagem de coagulante $(\mathrm{mg} / \mathrm{l})$

$\mathrm{k}=$ coeficiente de precipitação:

$\mathrm{k}=0,26$ (sulfato de alumínio líquido)

$\mathrm{k}=0,66$ (cloreto férrico anidro)

$\mathrm{k}=0,81$ (sulfato férrico)

$\mathrm{A}=$ outros aditivos, como carvão ativado em pó e polieletrólitos $(\mathrm{mg} / \mathrm{l})$

\section{APRESENTACÃO E ANÁLISE DOS RESULTADOS}

\section{Qantificação dos lodos das ETAs da RMSP}

Para a estimativa de geração atual de lodos das ETAs da RMSP foi empregada a fórmula proposta pela WRC (1), tendo-se utilizado os valores médios mensais de características da água bruta, dosagem de produtos químicos usados no tratamento e vazóes tratadas fornecidos pelas respectivas áreas operacionais, relativos ao ano de 2003 (Tabela 2). As Figuras 1 a 7 apresentam os valores de produção de sólidos (base seca) para cada uma das ETAs consideradas, podendo-se observar a variação mensal das quantidades de lodo geradas, confirmando sua relação com a variação das dosagens de produtos químicos empregados, estritamente relacionados com os parâmetros de qualidade da água a ser tratada.

A partir dos resultados apresentados nas Figuras 1 a 7 , pode-se verificar a grande variabilidade nos quantitativos de lodos gerados ao longo do período de um ano em cada ETA. Normalmente, há maior produção de lodo no período chuvoso, que vai de novembro a março, época em que há piora na qualidade geral das águas dos mananciais, representada pelos parâmetros turbidez e cor, necessitando, conseqüentemente, da aplicação de maiores quantidades de produtos químicos para o tratamento, notadamente de coagulantes. Para a ETA ABV, observam-se vários picos de geração de lodo ao longo do ano, e não só na estação chuvosa. Isto se deve ao fato de, esporadicamente, ser necessária a adição de carvão ativado em pó na água bruta, ocasionando o aumento da produção de lodo.
As implicações destas variações na produção de lodo ao longo do tempo são de significativa importância, não apenas para fins de planejamento de sua disposição final, mas também, para o dimensionamento do sistema de tratamento da fase sólida. Admitindose que o período hidrológico de um ano seja representativo das variaçōes de qualidade da água bruta e dosagens de coagulante, os valores de média mensal e anual de produção de lodo são razoáveis quando o objetivo principal é a utilização destes para fins de planejamento dos sistemas de transporte e disposição final. Por sua vez, quando do dimensionamento dos processos e operaçôes unitárias do sistema de tratamento da fase sólida, recomenda-se que sejam empregados valores diários, uma vez que os sistemas de equalização, adensamento e desidratação são projetados visando o processamento destes quantitativos durante um período de tempo de 24 horas.

A Figura 8 apresenta as comparaçôes da produção de lodo gerado por metro cúbico de água tratada para as

Tabela I - Previsão de aumento de capacidade nominal das ETAs do Sistema Integrado da RMSP (ENCIBRA; HIDROCONSULT, 2004)

\begin{tabular}{ccccccc}
\hline & \multicolumn{5}{c}{ ETA Capacidades nominais das ETAs $\left(\mathrm{m}^{3} / \mathrm{s}\right)$} \\
& & 2005 & 2010 & 2015 & 2020 & 2025 \\
\hline $\begin{array}{c}\text { Sem aumento } \\
\text { da produção }\end{array}$ & Guaraú & 33,0 & 33,0 & 33,0 & 33,0 & 33,0 \\
& Casa Grande & 4,0 & 4,0 & 4,0 & 4,0 & 4,0 \\
& Morro Grande & 1,2 & 1,2 & 1,2 & 1,2 & 1,2 \\
& Baixo Cotia & 1,0 & 1,0 & 1,0 & 1,0 & 1,0 \\
Com aumento & ABV & 14,0 & 16,0 & 16,0 & 16,0 & 16,0 \\
da produção & Rio Grande & 5,0 & 7,0 & 7,0 & 7,0 & 7,0 \\
& Taiaçupeba & 10,0 & 15,0 & 15,0 & 18,0 & 18,0 \\
\hline
\end{tabular}

Tabela 2 - Dados de dosagem de produtos químicos, cor e turbidez para o ano de 2003 (valores médios - SABESP) e cálculo da produção de lodo (base seca) pela fórmula da WRC

\begin{tabular}{cccccccccc}
\hline ETA & $\begin{array}{c}\text { Produção } \\
\text { Água } \\
\left(\mathrm{m}^{3} / \mathrm{s}\right)\end{array}$ & $\begin{array}{c}\text { Turbidez } \\
\text { média } \\
(\mathrm{UT})\end{array}$ & $\begin{array}{c}\text { Cor } \\
\text { média } \\
(\mathrm{uH})\end{array}$ & $\begin{array}{c}\text { Sulfato } \\
\text { Alumínio } \\
(\mathrm{mg} / \mathrm{l})\end{array}$ & $\begin{array}{c}\text { Sulfato } \\
\text { Férrico } \\
(\mathrm{mg} / \mathrm{l})\end{array}$ & $\begin{array}{c}\text { Cloreto } \\
\text { Férrico } \\
(\mathrm{mg} / \mathrm{l})\end{array}$ & $\begin{array}{c}\text { Polímero } \\
(\mathrm{mg} / \mathrm{l})\end{array}$ & $\begin{array}{c}\text { Carvão } \\
\text { Ativado } \\
(\mathrm{mg} / \mathrm{l})\end{array}$ & $\begin{array}{c}\text { P (sólidos- - } \\
\text { base seca) } \\
(\mathrm{kg} / \mathrm{dia})\end{array}$ \\
\hline Guaraú & 31,3 & 4,3 & 28 & 7,3 & 1,3 & - & 0,006 & - & 26.333 \\
ABV & 13,5 & 6,1 & 39 & - & 33,6 & 0,6 & 0,19 & 6,1 & 40.504 \\
Taiaçupeba & 9,6 & 6,5 & 51 & 16,5 & 12,7 & - & 0,21 & 1,0 & 18.212 \\
Rio Grande & 4,7 & 3,0 & 20 & - & 28,7 & - & 0,08 & 2,1 & 9.276 \\
Casa Grande & 3,92 & 3,6 & 41 & 22,5 & - & - & 0,05 & - & 4.423 \\
Morro Grande & 1,03 & 6,9 & 67 & 73,4 & - & - & 0,01 & - & 2.813 \\
Baixo Cotia & 0,88 & 18,6 & 136 & - & - & 69,6 & - & - & 4.562 \\
\hline
\end{tabular}




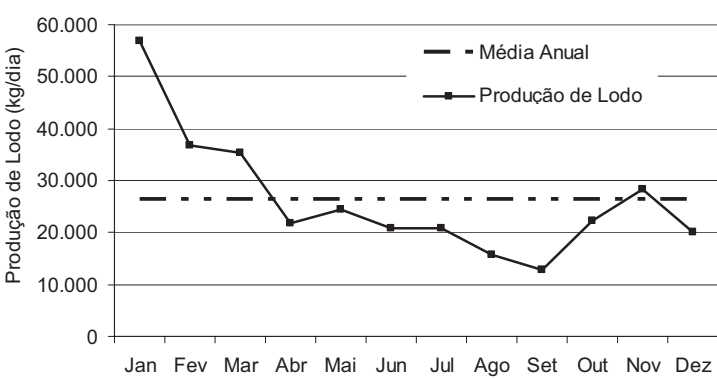

Figura I - ETA Guaraú - Médias mensais de produção de lodo (base seca) - ano 2003

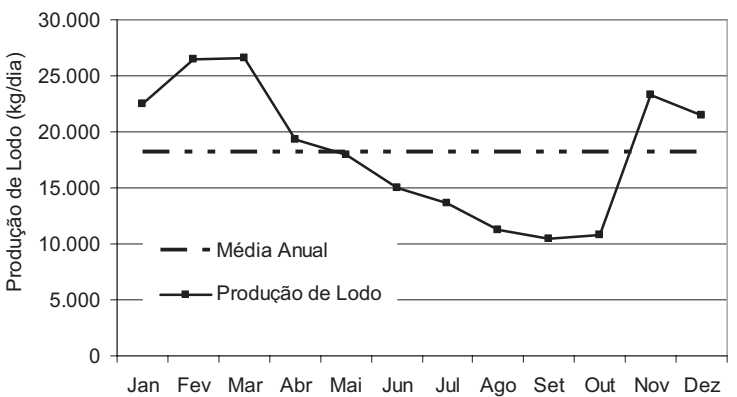

Figura 3 - ETA Taiaçupeba - Médias mensais de produção de lodo (base seca) - ano 2003

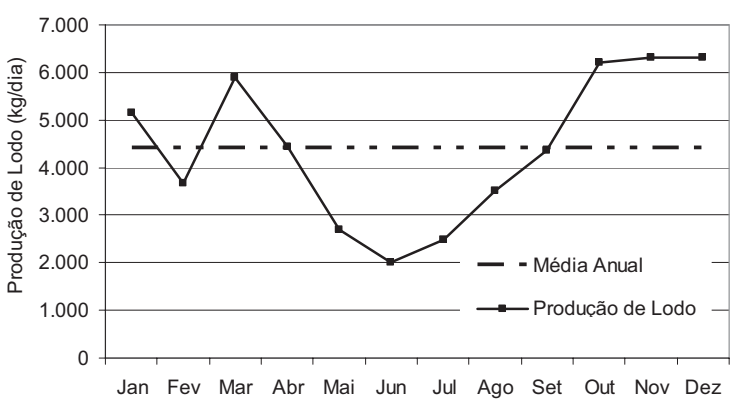

Figura 5 - ETA Casa Grande - Médias mensais de produção de lodo (base seca) - ano 2003

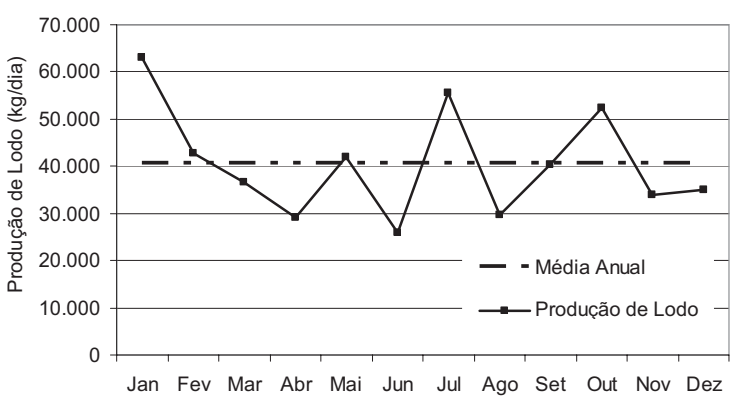

Figura 2 - ETA ABV - Médias mensais de produção de lodo (base seca) - ano 2003

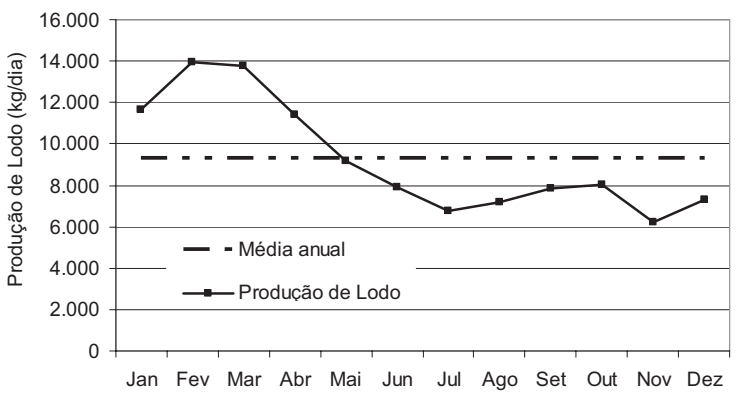

Figura 4 - ETA Rio Grande - Médias mensais de produção de lodo (base seca) - ano 2003

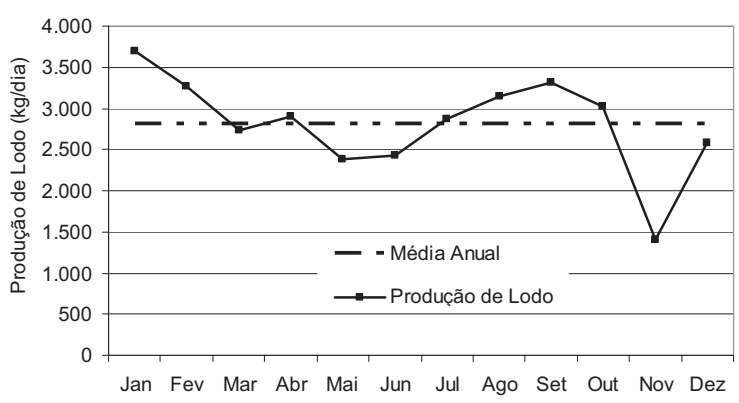

Figura 6 - ETA Morro Grande - Médias mensais de produção de lodo (base seca) - ano 2003

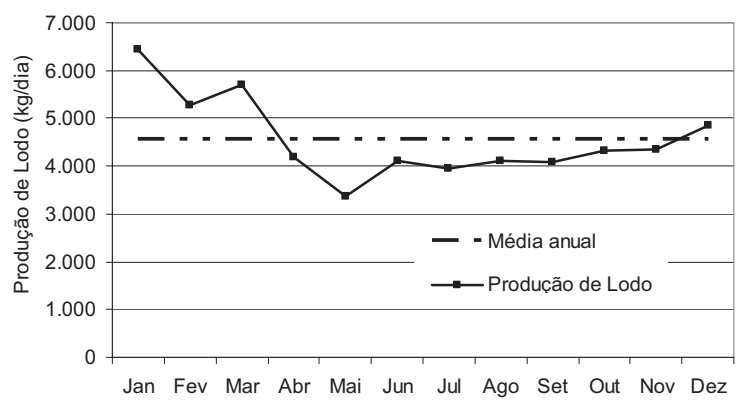

Figura 7 - ETA Baixo Cotia - Médias mensais de produção de lodo (base seca) - ano 2003 
sete ETAs da RMSP em estudo. A Tabela 3 apresenta um resumo dos quantitativos de lodos gerados na ETAs da RMSP calculados pela fórmula da WRC e sua previsão para o ano de 2025, tendo-se admitido que a produção de lodo por metro cúbico permaneça inalterada ao longo do tempo.

A partir da Figura 8, pode-se efetuar uma comparação da produção de lodo (base seca) por metro cúbico de água tratada de cada uma das ETAs. Notadamente, há maiores produçôes de lodo nas ETAs Baixo Cotia e ABV, $59,7 \mathrm{~g} / \mathrm{m}^{3}$ e $34,7 \mathrm{~g} / \mathrm{m}^{3}$ respectivamente, que são os sistemas que apresentam as piores qualidades de água em seus mananciais. Apesar do Sistema Alto Cotia apresentar uma água bruta de ótima qualidade em área protegida, a sua produção unitária de lodo também se apresenta elevada, $32 \mathrm{~g} / \mathrm{m}^{3}$ água, comparável à geração da ETA ABV, devido às dosagens relativamente altas de coagulantes que são utilizadas para o tratamento dos teores de cor elevados presentes em suas águas. As ETAs Guaraú e Casa Grande apresentam as menores geraçóes unitárias de lodo, $9,7 \mathrm{~g} / \mathrm{m}^{3}$ e $13,1 \mathrm{~g} / \mathrm{m}^{3}$ respectivamente, confirmando a boa qualidade das águas tratadas nestas ETAs com conseqüente utilização de dosagens menores de coagulantes em relação às outras ETAs da RMSP. Estes valores são condizentes com os apresentados por Reali (1999), que classificam a produção de lodo de acordo com a qualidade da água bruta.

Observando os valores apresentados na Tabela 3, nota-se que nem sempre as ETAs de maior capacidade hidráulica geram as maiores quantidades de lodo, já que essa geração depende diretamente da qualidade da água bruta. Isto significa afirmar que programas de melhoria e investimentos na qualidade da água diretamente na bacia hidrográfica apresentam não somente benefícios para a operação dos processos de tratamento de água como também na diminuição da produção de lodo, bem como de seus custos de tratamento, transporte e disposição final.

Para o ano de 2003, foi estimado um valor de produção de lodo seco para a RMSP em torno de 106,1 t/dia, ao passo que, para o ano de 2025 , este apresenta um incremento de $28,6 \%$, aumentando para 136,4 t/dia. Considerando as eficiências médias habitualmente conseguidas nos equipamentos de adensamento e desidratação já empregados em testes e em operação, pode-se adotar um valor de teor de sólidos esperado e massa específica para o lodo desidratado em torno de $30 \%$ e $1,20 \mathrm{t} / \mathrm{m}^{3}$, respectivamente. Desta forma, tem-se que a massa "úmida" e volume de lodo estimado para o ano de 2025 para a RMSP deverão situar-se em torno de $454,7 \mathrm{t} / \mathrm{dia}$ e $378,9 \mathrm{~m}^{3} / \mathrm{dia}$, respectivamente.

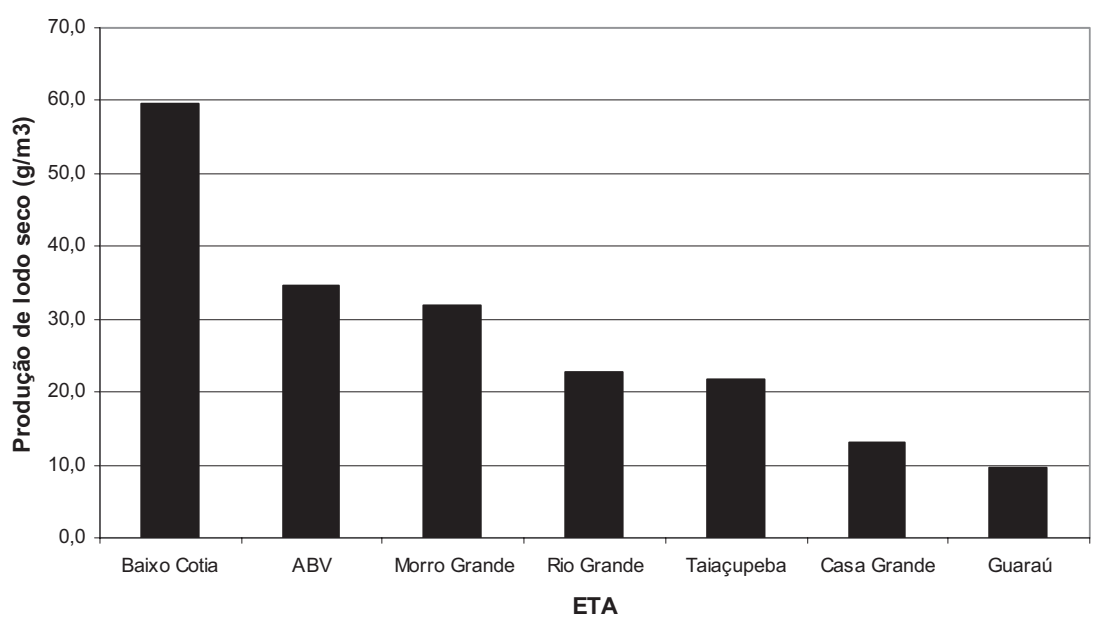

Figura 8 - ETAs da RMSP - Lodo gerado (base seca) por metro cúbico de água tratada (g/m³ água) - médias (fórmula da WRC) - ano 2003

Tabela 3 - Resumo dos quantitativos de lodos gerados calculados pela fórmula da WRC para as ETAs da RMSP nos anos de 2003 e 2025

\begin{tabular}{cccccc}
\hline ETA & $\begin{array}{c}\text { Vazão } \\
\text { média } \\
2003\left(\mathrm{~m}^{3} / \mathrm{s}\right)\end{array}$ & $\begin{array}{c}\text { Vazão } \\
\text { média } \\
2025\left(\mathrm{~m}^{3} / \mathrm{s}\right)\end{array}$ & $\begin{array}{c}\text { Lodo } \\
\text { gerado } \\
\left(\mathrm{g} / \mathrm{m}^{3} \text { água }\right)\end{array}$ & $\begin{array}{c}\text { Produção de lodo } \\
(\text { base seca }) \\
(2003)-(\mathrm{t} / \mathrm{dia})\end{array}$ & $\begin{array}{c}\text { Produção de } \\
\text { lodo (base seca) } \\
(2025)-(\mathrm{t} / \mathrm{dia})\end{array}$ \\
\hline Guaraú & 31,3 & 33,0 & 9,7 & 26,3 & 27,7 \\
ABV & 13,5 & 16,0 & 34,7 & 40,5 & 48,0 \\
Taiaçupeba & 9,6 & 18,0 & 21,8 & 18,2 & 33,9 \\
Rio Grande & 4,7 & 7,0 & 22,8 & 9,3 & 13,8 \\
Casa Grande & 3,9 & 4,0 & 13,1 & 4,4 & 4,5 \\
Morro Grande & 1,0 & 1,2 & 32,0 & 2,8 & 3,3 \\
Baixo Cotia & 0,9 & 1,0 & 59,7 & 4,6 & 5,2 \\
TOTAL & 64,9 & 80,2 & & 106,1 & 136,4 \\
\hline
\end{tabular}


A ordem de grandeza destes valores é significativa, uma vez que a tendência ao longo do tempo é a elevação dos custos para o transporte e destinação final do lodo, bem como a escassez de áreas disponíveis para a sua disposição. Assim sendo, faz-se necessário um planejamento integrado das alternativas de tratamento dos lodos e destinação final para todas as ETAs da RMSP conjuntamente e não isoladamente.

Uma das maiores dificuldades para a maior parte das ETAs brasileiras é a ausência de dados que permitam o cálculo da produção de lodo de forma segura, bem como o fato de que a sua geração está diretamente associada a variabilidade temporal da qualidade da água bruta. Portanto, torna-se altamente recomendável que as ETAs atualmente em operação que possuam demandas ambientais com respeito aos seus resíduos gerados estabeleçam um programa de obtenção de dados de qualidade de água bruta e de dosagens de produtos químicos que permitam o cálculo de sua produção de lodo ao longo de um período hidrológico significativo, oferecendo subsídios para a definição e seleção de alternativas para sua destinação final.

\section{Avaliação geral das alternativas tecnológicas disponíveis para disposição final dos lodos das ETAs da RMSP}

Para os lodos das ETAs da RMSP estudadas, os métodos disponíveis de uso e disposição final podem ser resumidos em:

- Disposição em aterros particulares, municipais ou exclusivos;

- Aplicação no solo para estabilização, para agricultura e para recuperação de áreas degradadas;

- Reciclagem do lodo da ETA em produção de material cerâmico ou cimento;

- Lançamento em sistemas de coleta, afastamento e tratamento de esgotos sanitários;

- Recuperação de coagulantes;

- Incineração.

\section{- Disposição em aterros sanitários}

No Brasil, a NBR 10.004 tem sido utilizada para licenciar e operar aterros sanitários, estendendo-se seus conceitos para enquadramento dos lodos de ETAs e ETEs e suas respectivas disposições nesses aterros. As caracterizaçōes realizadas em alguns estudos (SABESP, 2002) enquadraram os lodos das ETAs da RMSP como Classe II (não inerte).

A disposição do lodo em aterros Classe II é alternativa bem conhecida, sendo um método seguro para a saúde pública e ambiental quando corretamente projetado e operado, podendo ser viabilizada a partir de aterros existentes ou da implantação de aterros exclusivos. No caso de aterros particulares ou municipais, a disposição dos lodos desidratados implica em custos de transporte e disposição e, no caso de aterros exclusivos, em custos de implantação, operação e transporte até o local. Os custos médios de transporte e disposição final de lodos em aterros particulares na RMSP situam-se em torno de $\mathrm{R} \$ 60,00$ a $\mathrm{R} \$ 80,00$ por tonelada de lodo desidratado.

As dificuldades encontradas para implantação de aterros, notadamente na RMSP, são a necessidade de grandes áreas adjacentes aos centros geradores de resíduos e a escassez de áreas adequadas que não causem impactos ao meio ambiente $\mathrm{e}$ às comunidades circunvizinhas.

A alternativa de disposição dos lodos de ETAs em aterros, sejam exclusivos ou não, é sempre recomendada por ser comprovadamente viável tecnicamente e possuir regulamentação pelas legislações ambientais vigentes. Mesmo adotando-se outras alternativas de disposição, propõe-se sempre prever a utilização de aterros sanitários como opção de armazenamento dos lodos, pois pode haver necessidade de sua utilização nos casos de variações bruscas na quantidade ou qualidade dos lodos, a fim de absorver a produção excedente, e nas eventuais contingências referentes a restriçōes no tráfego de veículos pesados na área ou eventual paralisação da alternativa escolhida (uso benéfico ou não) em função de restrições de mercado, restriçôes sazonais ou impedimentos legais e institucionais.

Dessa maneira, a solução aterro (particular, municipal ou exclusivo) não pode ser cotejada sob prisma meramente comparativo, devendo ser focada como um complemento da solução a ser implementada ao final.

\section{- Uso de lodos em solos}

Nos Estados Unidos, há alguns exemplos de aplicação de lodos de ETAs que utilizam sais de ferro e alumínio em solos para agricultura, em áreas florestais e para recuperação de áreas degradadas. A viabilidade desta aplicação é determinada pelas características físicas e químicas dos lodos, notadamente pela existência de nutrientes benéficos às culturas e pela ausência de contaminantes (Dayton et al, 2001).

Por ser gerado em processos de tratamento físico-químico, não envolvendo processos biológicos, a aplicação do lodo de ETAs diretamente no solo para benefício agrícola deve ser claramente demonstrada através de ensaios específicos. Apesar de conter certo teor de matéria orgânica, os lodos de ETAs normalmente não são atrativos para disposição direta no solo.

\section{- Uso de lodos na fabricação de material cerâmico}

Nos últimos anos, têm sido realizados estudos para o aproveitamento e reciclagem do lodo produzido em ETAs utilizando-o na produção de material cerâmico. O objetivo é buscar alternativas que proporcionem a utilização do lodo da ETA de maneira mais completa, no conceito de reciclagem, e ágil, considerando-se o tempo necessário para a implantação e operação de aterros exclusivos para a disposição final desse resíduo.

Há estudos em desenvolvimento com o objetivo de verificar, principalmente, a viabilidade técnica da utilização do lodo de ETA em produtos cerâmicos, podendo, a partir daí, avaliar o aspecto econômico sob os enfoques da concessionária de serviços de saneamento e da indústria cerâmica. Estima-se um custo de $\mathrm{R} \$ 35,00$ por tonelada de lodo incorporado na produção de material cerâmico, valor este que abrange os custos de transporte e disposição nas jazidas de argila (Morita et al, 2002).

Pesquisas realizadas no Brasil concluíram que os lodos de ETAs desidratados podem ser utilizados na produção de material cerâmico, principalmente para os que se destinam à construção civil sem função estrutural, numa proporção de aproximadamente $10 \%$ de lodo em relação à massa de argila. Para este uso benéfico, é desejável que os lodos tenham suas características físico-químicas relativamente constantes. Para viabilizar a utilização do lodo, este não deve interferir nos processos de produção e os produtos resultantes devem atender aos 
requisitos técnicos mínimos (Campos, 2001; Ramires et al, 2001).

A utilização do lodo gerado no mercado dependerá, principalmente, da aceitação e do seu custo por parte das indústrias cerâmicas e consumidores finais. Esse custo dependerá das condições em que as cerâmicas obtêm sua matéria prima (distância da jazida e aspectos ambientais) e daquelas que a companhia de saneamento poderá oferecer (transporte até a indústria ou retirada na ETA e vantagem econômica para a indústria).

- Lançamento de lodo de ETAs em sistemas de coleta e tratamento de esgotos

O lançamento de lodos de ETAs para tratamento em ETEs constitui-se em um destino adequado e sua utilização depende de fatores econômicos e logísticos, como a existência de uma ETE nas proximidades da ETA em condiçóes técnicas de receber os resíduos e a disponibilidade de meio adequado para seu transporte desde a ETA até a ETE (Melo et al, 2002).

A princípio, o envio de lodos de ETAs para ETEs é uma solução tecnicamente viável, uma vez que as operações de tratamento de ambas as fases sólidas serão concentradas em uma única unidade de tratamento, com significativa economia de escala nos seus custos operacionais. No entanto, considerando que as ETEs podem possuir diferentes concepçôes com respeito a seus processos unitários, cada um destes tem que ser avaliado individualmente quanto aos seus prováveis impactos no tocante ao processamento dos sólidos em suspensão totais (SST), bem como na eventual interferência nos processos biológicos de tratamento aeróbio e anaeróbio (Carvalho et al, 1999; Brinck, 2003).

De qualquer modo, deve ser enfatizado que a disposição de lodos de ETAs em ETEs não representa uma solução de custo zero, uma vez que, mesmo sendo possível o processamento de uma maior quantidade mássica de lodo, a ETE deverá ser preparada para o aumento do volume de lodo que deverá ser processado em seu sistema de desidratação, bem como nos seus custos de transporte e disposição final.

Aliado ao fato de ser absolutamente fundamental uma análise da ETE, também se faz necessária avaliar o projeto e operação da ETA, especialmente como são efetuadas as descargas de lodo dos decantadores, como estes são operados e a interface com as características da rede coletora de esgotos sanitários local. A avaliação das condições hidráulicas do sistema de coleta de esgotos sanitários é de significativa importância, uma vez que a mesma deverá ser capaz de veicular as vazões de descarga da ETA, bem como ser operada de forma a não permitir que ocorra a sedimentação dos SST ao longo de suas partes constitutivas. Torna-se recomendável, no mínimo, a equalização do lodo gerado nos decantadores antes de seu lançamento no sistema público de coleta de esgotos sanitários, o que, por si só, já representa a necessidade de investimentos na ETA.

Esta alternativa é particularmente atraente quando não há áreas disponíveis na ETA para a implantação do sistema de tratamento de lodos (adensamento e desidratação) ou quando a ETA se encontra em área densamente urbanizada onde o transporte do lodo desidratado por caminhōes pode causar transtornos ao trânsito local.

\section{- Incineração}

A incineração é um método dispendioso, sendo que os custos podem chegar a $\mathrm{R} \$ 2.000,00$ por tonelada de lodo desidratado (SABESP, 2002). Algumas análises efetuadas demonstraram que o lodo de ETA tem poder calorífico baixo gerando, aproximadamente, $10 \%$ a $15 \%$ de cinzas a $600{ }^{\circ} \mathrm{C}$ (SABESP, 2002). O método não será considerado por constituir-se numa alternativa muito dispendiosa, por não eliminar a fase de desidratação dos lodos e por não resolver integralmente o problema, já que restam cinzas a serem dispostas em aterro, apesar de diminuir significativamente seus volumes finais.

\section{Avaliação técnica das alternativas possíveis para cada ETA da RMSP}

A partir de uma primeira avaliação das práticas existentes de uso e disposição de lodos, foi feita uma seleção das possíveis tecnologias de beneficiamento ou disposição final aplicáveis ao caso das ETAs da RMSP. Esta avaliação fundamentou-se no fato de que uma tecnologia, para ser aplicável, deve atender aos seguintes requisitos:
- Possuir capacidade de processamento compatível com a quantidade gerada de sólidos, dados os quantitativos a serem produzidos na RMSP.

- Estar devidamente desenvolvida em termos tecnológicos e existirem exemplos de aplicações que comprovem a validade do desenvolvimento.

- Ser aplicável no caso da RMSP, considerando as particularidades existentes.

A seguir, em função dos requisitos citados, apresentam-se, para cada ETA, as alternativas consideradas.

\section{•ETA Guaraú}

A ETA Guaraú foi construída no final da década de 60, dispondo de um sistema de recuperação integral da água de lavagem dos filtros e de decantadores do tipo convencional dotados de sistemas de remoção semi-contínua dos lodos gerados. Embora seja a ETA com maior capacidade hidráulica $\left(33,0 \mathrm{~m}^{3} / \mathrm{s}\right)$, a sua produção de lodo seco não é a maior da RMSP, situando-se em torno de 27,0 t/dia (base seca). Como não está previsto o aumento de sua capacidade hidráulica para 2025, a produção de lodo tenderá a ser a mesma.

Para a ETA Guaraú, em função de sua localização geográfica e por estar situada em área abrangida por uma estação de tratamento de esgotos (ETE Barueri), o lodo pode ser disposto na rede coletora de esgotos sanitários para posterior tratamento e disposição final conjunta com os de origem sanitária. A grande vantagem na adoção desta alternativa está relacionada a não necessidade de implantação de sistemas de tratamento da fase sólida nas dependências da ETA e a concentração das operações de adensamento e desidratação em uma única unidade (ETE Barueri), o que incorrerá em menores custos operacionais e de mão de obra.

No entanto, conforme já dito anteriormente, deverá ser considerado o fato de que a referida ETE deverá ser preparada para o recebimento de uma maior carga de sólidos no afluente, o que irá exigir investimentos em seu sistema de desidratação e maiores custos com o seu transporte e disposição final. Além disso, espera-se que ocorra uma alteração na qualidade físico-química do lodo final desidratado, o que deverá impor restrições com relação ao seu uso para fins agrícolas. Em face das severas restriçōes ambientais impostas 
com respeito ao uso agrícola dos lodos gerados nas ETEs da RMSP, bem como da ausência de mercado consumidor nas proximidades do centro gerador de resíduos, não se acredita que este fato seja o maior impedimento quanto à adoção desta alternativa, uma vez que, atualmente, os lodos produzidos são enviados para aterros sanitários Classe II.

Outra possibilidade é a implantação de um sistema independente para manuseio e desidratação de lodo na área da ETA Guaraú e posterior envio do lodo desidratado para aterros sanitários ou para indústrias cerâmicas. Esta alternativa de implantação de unidades de tratamento da fase sólida nas dependências da ETA é possível, uma vez que a mesma possui área disponível para tanto. Assim sendo, o lodo final desidratado pode ser encaminhado para aterros sanitários municipais ou particulares ou para indústrias cerâmicas, uma vez que a água bruta proveniente dos mananciais que abastecem a ETA Guaraú apresenta uma grande estabilidade físico-química ao longo do tempo e, por serem mananciais relativamente protegidos e com reduzida influência antrópica, também os lodos gerados no processo de tratamento apresentam características constantes, sendo altamente viável a sua utilização no processo de fabricação de materiais cerâmicos.

Mesmo assim, deve-se sempre ter a possibilidade de envio do lodo a aterros quando este não atender aos requisitos necessários para sua incorporação ao material cerâmico. De acordo com as considerações feitas, esta primeira avaliação não pode apontar a alternativa mais favorável nem descartar alternativas. Assim, considera-se que as três alternativas são viáveis e devem ser avaliadas criteriosamente.

\section{- ETA Alto da Boa Vista (ABV)}

A ETA ABV foi construída na década de 40 em uma regiāo com baixa densidade demográfica e relativamente afastada do município de São Paulo. No entanto, em função do seu crescimento acelerado a partir da década de 60 , atualmente, a mesma encontra-se em uma região altamente urbanizada e com uma população residente de elevado poder aquisitivo. Para seu sistema de tratamento e disposição de lodos podem ser avaliadas duas opçôes: o encaminhamento para a rede coletora de esgotos sanitários e tratamento conjunto com o esgoto sanitário também na ETE Barueri ou a implantação de um sistema de adensamento e desidratação na área da própria ETA com posterior envio do lodo a aterros sanitários. Como a ETA ABV utiliza carvão ativado em pó em vários períodos do ano para controle de gosto e odor na água bruta, a alternativa de aproveitamento de seus lodos na indústria cerâmica torna-se inviável, uma vez que as suas características não tenderiam a serem constantes ao longo do ano.

A implantação de um sistema de tratamento da fase sólida nas dependências da ETA ABV teria como principais desvantagens o fato de necessitar-se de uma área junto à mesma para a construção das unidades de adensamento e desidratação e, aliado a este problema, deve-se considerar ser esta a ETA da RMSP com maior produção de lodo $(40,5 \mathrm{t} / \mathrm{dia})$ e se for assumido um teor de sólidos no lodo desidratado de 30\%, tem-se que o volume de lodo úmido a ser transportado por dia é da ordem de $113 \mathrm{~m}^{3} / \mathrm{dia}$, o que corresponde à movimentação de 23 caminhões em um dia. Como se prevê para a ETA $\mathrm{ABV}$ o aumento de sua vazão para $16,0 \mathrm{~m}^{3} / \mathrm{s}$, a sua produção de lodo deverá ser aumentada para 48,0 t/dia, o que agravará os seus problemas de manuseio e transporte.

Dado os inúmeros inconvenientes que o transporte dos lodos desidratados poderá gerar na vizinhança da ETA, que se localiza em área densamente urbanizada, a tendência é que os lodos da ETA ABV sejam encaminhados via rede coletora de esgotos sanitários para tratamento na ETE Barueri. Considerando que o balanço de massa para a ETA ABV e ETE Barueri demonstraram que o acréscimo de sólidos em suspensão totais no afluente a ETE não seria superior a $10 \%$, sendo este passível de ser processado em suas unidades de tratamento, esta opção de destinação final dos lodos torna-se bastante atrativa.

\section{- ETA Taiaçupeba}

A ETA Taiaçupeba é dotada de sistemas de tratamento destinados ao manuseio, adensamento e desidratação dos lodos gerados. Com isto e em função da existência de uma equipe já treinada na operação dos sistemas de adensamento e desidratação, a princípio, a solução mais razoável a ser adotada é a ampliação deste sistema, a fim de que o mesmo seja capaz de processar os lodos gerados para as vazóes futuras previstas de $15,0 \mathrm{~m}^{3} / \mathrm{s}$ e $18,0 \mathrm{~m}^{3} / \mathrm{s}$. Deste modo, o aumento da produção de lodo, que deverá ocorrer na mesma proporção $(18,2 \mathrm{t} /$ dia para 33,9 t/dia), irá requerer uma atenção especial no tocante à solução a ser adotada com respeito ao seu tratamento e disposição final.

Os lodos, uma vez desidratados, podem ser encaminhados a aterros particulares ou exclusivos, bem como serem enviados para a incorporação no processo de fabricação de material cerâmico nos períodos em que a ETA não utilizar carvão ativado em pó (CAP) no seu processo de tratamento.

A ETA Taiaçupeba é um excelente exemplo em que podem ser consideradas diferentes possibilidades para a disposição dos seus lodos, sendo a solução final função das características da água bruta e do processo de tratamento, uma vez que, nos períodos em que houver a aplicação de CAP na água bruta, o lodo deverá ser encaminhado a aterros particulares ou exclusivos e, quando não houver a necessidade de sua aplicação, o lodo poderá, eventualmente, ser encaminhado para a indústria cerâmica.

\section{- ETA Rio Grande}

Atualmente, a ETA Rio Grande trata uma vazão de, aproximadamente, $4,8 \mathrm{~m}^{3} / \mathrm{s}$ e, de acordo com o PDAA, a sua capacidade hidráulica deverá ser aumentada para $7,0 \mathrm{~m}^{3} / \mathrm{s}$. Atualmente, a sua produção de lodo situa-se em torno de 9,3 t/dia e, para o ano de 2025, espera-se que esteja na faixa de $13,8 \mathrm{t} / \mathrm{dia}$.

Uma vez que a área disponível na ETA Rio Grande será futuramente empregada na construção de unidades adicionais de floculação, sedimentação e filtração, não há condições de implantar um sistema de tratamento dos resíduos gerados.

Com relação à disposição final dos seus lodos, pretende-se encaminhálos para tratamento conjunto com os esgotos sanitários em uma estação de tratamento de esgotos (ETE ABC). Essa solução permitirá que se utilize a capacidade ociosa atual daquela ETE, sem grandes impactos no processo de tratamento de esgotos.

Uma vez que a ETA Rio Grande situa-se em uma região desprovida de rede coletora de esgotos sanitários, foi 
necessária a implantação de uma linha de afastamento de lodo em direção a ETE ABC e, quando de sua operação, será possível avaliar os reais impactos causados no tratamento de esgotos e, se for o caso, projetar uma solução tradicional, como um sistema de desidratação de lodo próprio e independente.

\section{- ETA Casa Grande}

A ETA Casa Grande possui área disponível em seus domínios e encontra-se relativamente afastada da RMSP, dificultado o envio de seus lodos a sistemas de coleta e afastamento de esgotos para posterior processamento em ETE. Deste modo, propõe-se implantar unidades específicas para adensamento e desidratação de lodos para posterior disposição final.

Comparativamente com as demais ETAs da RMSP, a sua produção de lodo seco é relativamente pequena, da ordem de 4,4 t/dia, o que torna mais fácil sua operação de transporte e destinação final. A água bruta é de boa qualidade, sem variações bruscas ao longo do ano, proporcionando a geração de lodos com características relativamente constantes. Os lodos desidratados poderiam ser encaminhados a aterros sanitários ou utilizados na indústria cerâmica.

\section{- ETA Morro Grande}

Do mesmo modo que a ETA Casa Grande, a ETA Morro Grande também se encontra distante da RMSP, com área disponível para a construção de unidades de adensamento e desidratação. A sua produção de lodo também pode ser considerada pequena, com valores variando de 2,8 t/dia a 3,3 t/dia.

Uma vez que também não é exeqüível a disposição de seus lodos para tratamento em ETE, seja por não haver rede coletora disponível no local, bem como de ETE em sua bacia de drenagem, a alternativa mais viável é a construção de uma unidade própria de tratamento da fase sólida e posterior encaminhamento dos lodos desidratados a aterros sanitários ou indústria cerâmica.

\section{- ETA Baixo Cotia}

A ETA Baixo Cotia trata uma água bruta de qualidade variável no tempo, com períodos de elevada turbidez e cor aparente. Este fato indica que os lodos gerados em suas unidades apresentem características fisico-químicas variáveis e de difícil controle. Ainda que sua capacidade hidráulica seja a menor de todas que abastecem a RMSP, a sua produção de lodo por metro cúbico é a mais elevada $\left(59,7 \mathrm{~g} / \mathrm{m}^{3}\right)$, o que proporciona uma produção de lodo em torno de $4,6 \mathrm{t} / \mathrm{dia}$ a $5,2 \mathrm{t} / \mathrm{dia}$.

Dado que a ETA Baixo Cotia dista menos de $2 \mathrm{~km}$ da ETE Barueri, propõe-se que os lodos gerados sejam lançados no coletor tronco de esgotos existente que margeia o rio Cotia e que sejam conduzidos a ETE para tratamento em conjunto com os esgotos sanitários.

As alternativas factíveis de disposição final dos lodos gerados nas ETAs consideradas estão apresentadas na Tabela 4. É interessante observar que, em função da complexidade do sistema de abastecimento de água da RMSP (elevado número de ETAs e águas brutas com diferentes qualidades físico-químicas), não se pode afirmar que exista uma solução única para o tratamento e disposição final de seus lodos.

Cada ETA, ao contrário, tem que ser avaliada individualmente em função de suas características particulares de quantidades de geração e qualidade dos lodos, possibilidade de construção de unidades de tratamento de fase sólida, custos de transporte e disposição final, existência de rede coletora de esgotos sanitários e possibilidade de envio para tratamento em ETE. A definição da alternativa mais conveniente não pode ser efetuada apenas considerando os aspectos técnicos e econômicos, mas, também, as condicionantes ambientais, sociais e políticas.

Tabela 4 - Alternativas de uso e disposição de lodos para cada ETA

\begin{tabular}{cccc}
\hline ETA & Aterro sanitário & $\begin{array}{c}\text { Incorporação em } \\
\text { material cerâmico }\end{array}$ & $\begin{array}{c}\text { Lançamento em } \\
\text { sistema de esgotos }\end{array}$ \\
\hline Guaraú & $\operatorname{sim}$ & $\operatorname{sim}$ & $\operatorname{sim}$ \\
ABV & & & $\operatorname{sim}$ \\
Taiaçupeba & $\operatorname{sim}$ & $\operatorname{sim}$ & $\operatorname{sim}$ \\
Rio Grande & & $\operatorname{sim}$ & $\operatorname{sim}$ \\
Casa Grande & $\operatorname{sim}$ & $\operatorname{sim}$ & \\
Morro Grande & $\operatorname{sim}$ & & $\operatorname{sim}$ \\
Baixo Cotia & & &
\end{tabular}

\section{CONCLUSÕES E RECOMENDAÇỖES FINAIS}

Com base no exposto, pode concluir-se que:

- As ETAs da RMSP geram quantitativos de lodos diferentes de acordo com a qualidade da água bruta e dosagens de produtos químicos empregados em sua operação. Observou-se que os valores de produção de lodo (base seca) por metro cúbico de água tratada variaram de $10 \mathrm{~g} / \mathrm{m}^{3}$ a $60 \mathrm{~g} / \mathrm{m}^{3}$, tendo sido os menores valores obtidos para ETAs que tratam águas de melhor qualidade e vice-versa.

- Observou-se uma grande variabilidade nos quantitativos de lodos gerados ao longo do período de um ano em cada ETA. Normalmente, ocorreu uma maior produção de lodo no período chuvoso, que vai de novembro a março, época em que há piora na qualidade geral das águas dos manan- ciais, representada pelos parâmetros cor aparente e turbidez, necessitando, conseqüentemente, da aplicação de maiores quantidades de produtos químicos para o tratamento, notadamente de coagulantes.

- A geração de lodo das sete ETAs da RMSP em 2003 foi de 106,1 t/dia (base seca), devendo aumentar para $136,4 \mathrm{t} / \mathrm{dia}$ (base seca) em 2025, ou seja, um aumento de 28,6\%, acompanhando o crescimento da produção de água tratada.

- As possibilidades de disposição final para os lodos das ETAs da RMSP podem ser resumidas em disposição em aterros particulares, municipais ou exclusivos, reciclagem do lodo em produção de material cerâmico e lançamento em sistemas de coleta e afastamento de esgotos sanitários para posterior processamento em ETEs.

- Em face da complexidade da RMSP, observa-se que não pode ser 
identificada uma solução única para o tratamento e disposição final dos lodos de suas ETAs, devendo cada uma das opções ser ponderada para cada ETA individualmente, em função de seus aspectos técnicos, econômicos, ambientais, sociais e políticos.

\section{REFERÊNCIAS}

ASCE; AWWA; U.S. EPA. Technology transfer handbook: management of water treatment plant residuals. New York: ASCE; Denver, CO: AWWA. 294p. 1996.

BRINCK, N.C.P. Desaguamento mecânico de lodos de estação de tratamento de esgotos em conjunto com lodos de estação de tratamento de água. Dissertação (Mestrado) - Escola Politécnica, Universidade de São Paulo. São Paulo. 347p. 2003

CAMPOS, M.R.F. (coordenadora). Estudos para a reciclagem de lodo de ETA para produção de material cerâmico. SABESP. São Paulo, 2001.

CARVALHO, E.H.; DI BERNARDO, L. Interferência dos despejos de estaçôes de tratamento de água nas estacōes de tratamento de esgotos. In: $20^{\circ}$ CONGRESSO BRASILEIRO DE ENGENHARIA SANITÁRIA E AMBIENTAL, Rio de Janeiro. ABES. 1999.

CORNWELL, D.A.; KOPPERS, H.M.M. Slib, schlamm, sludge. Denver, CO: American Water Works Association Research Foundation; KIWA Ltd, 308p, 1990.
CORNWELL, D A ; MUTTER, RN ; VANDERMEYDEN, C. Commercial application and marketing of water plant residuals. Denver, CO: American Water Works Association Research Foundation; American Water Works Association, 187 p, 1999.

DAYTON, E.A.; BASTA, N.T. Characterization of drinking water treatment residuals for use as a soil substitute. J. Water Environment Research, vol. $73, \mathrm{n}^{\circ}$ 1, Jan/Feb, Water Environment Federation, 2001.

ENCIBRA S. A. ESTUDOS E PROJETOS DE ENGENHARIA; HIDROCONSULT CONSULTORIA, ESTUDOS E PROJETOS S.A. Revisão e Atualização do Plano Diretor de Abastecimento de Água da RMSP. São Paulo. (Estudo Técnico ENCIBRAHIDROCONSULT/SABESP). 2004.

MELO, A.A.; LOVO, E.; BUENO, R.C.R. Recebimento de lodo de ETA em uma ETE. In: XIII ENCONTRO TÉCNICO AESABESP, São Paulo. Anais. AESABESP. 2002

MORITA, D.M. et al. Incorporação de lodos de estaçôes de tratamento de água em blocos cerâmicos. Revista SANEAS, vol. 1, $\mathrm{n}^{\circ}$ 14. AESABESP. 2002.

RAMIRES, M.V.V. et al. Incorporação do resíduo (lodo) da ETA de São Leopoldo - RS nas misturas de argilas para a fabricação de componentes ceramicos conformados por prensagem. In: $45^{\circ}$ CONGRESSO BRASILEIRO DE CERÂMICA, Florianópolis. Anais. 2001

REALI, M.A.P. (coordenador). Noçôes gerais de tratamento e disposição final de lodos de estaçóes de tratamento de água. Projeto PROSAB. Rio de Janeiro: ABES, 250p. 1999.
SABESP Relatório Ambiental Preliminar (RAP) do aterro exclusivo para disposição de lodo da ETA Taiaçupeba. São Paulo. (Estudo Técnico SABESP). 2002

SARON, A.; LEITE, V.M.B. Quantificação de lodo em estação de tratamento de Água. In: $21^{\circ}$ CONGRESSO BRASILEIRO DE ENGENHA RIA SANITÁRIA E AMBIENTAL, João Pessoa. Anais. ABES. 2001.

\section{Endereço para correspondência:}

Gladys Fernandes Januário

Departamento de Engenharia

Hidráulica e Sanitária

Escola Politécnica da

Universidade de São Paulo

Av. Prof. Almeida Prado, Travessa

2, n.27I

Prédio de Engenharia Civil

Cidade Universitária - São Paulo

05508-900 São Paulo - SP - Brasil

Tel.: (I I) 309 I-5220/309 I-5444

E-mail: gladysfj@uol.com.br 